\title{
PERAMALAN JUMLAH KASUS INFEKSI SALURAN PERNAFASAN AKUT (ISPA) PADA LAKI-LAKI TAHUN 2019 DENGAN METODE ARIMA
}

\section{FORECASTING NUMBER OF CASES OF ACUTE RESPIRATORY INFECTION (ARI) IN 2019 USING ARIMA METHOD}

\author{
Moch. Fitriawan Eka Saputra ${ }^{1}$, Muhammad Rizky ${ }^{2}$ \\ ${ }^{1}$ Departemen Biostatistika dan Kependudukan \\ Fakultas Kesehatan Masyarakat Universitas Airlangga \\ Kampus C, Mulyorejo, Kota Surabaya, Jawa Timur, 60115 \\ ${ }^{2}$ Puskesmas Jagir Surabaya \\ Jl. Bendul Merisi No.1, Jagir, Wonokromo, Kota Surabaya, Jawa Timur, 60244 \\ Alamat Korespondesi: Moch. Fitriawan Eka Saputra \\ E-mail: fitriawaneka@gmail.com
}

\begin{abstract}
The ARIMA method is an approach that forms the most powerful model in analyzing time series data, and the studies given are very thorough. This method can be modeling data stationary or not stationary, it can be seen from sine wave shape of the plot ACF. This method is used because obtained the results are better and more accurate. According to WHO, Acute Respiratory Infection (ARI) is an infectious disease that causes can be morbidity and mortality. A four million people die each year. This study used secondary data so that it is categorized as non reactive research. The population were cases of Acute Respiratory Infections (ARI) at Jagir Health Center Surabaya which were recorded in 2013 to 2018 (monthly). The dependent variable is the cases of Acute Respiratory Infection (ARI), while the independent variable is time. The model that was obtained from the ARIMA method is a model $(2.0,1)$. The forecasting result is 354 cases in 2019, the forecasting has increased from 2018 to only 313 cases. It was a suggestion that the forecasting result can be a reference for developing a policy and a new program or improvement in previous program so that the number cases of ARI at the Jagir Health Center can be resolved properly.
\end{abstract}

Keywords: forecasting, autoregressive intregated moving average, acute respiratory tract infection

\begin{abstract}
ABSTRAK
Metode ARIMA adalah suatu pendekatan yang membentuk model yang paling kuat dalam menganalisis data time series, serta kajian yang diberikan sangatlah teliti. Metode ini dapat memodelkan data yang stasioner ataupun yang tidak stasioner, yang dapat dilihat dari plot ACF yang berbentuk gelombang sinus. Metode ini dipakai karena hasil yang didapat lebih baik dan akurat. Menurut WHO, Infeksi Saluran Pernafasan Akut (ISPA) merupakan penyakit menular yang menyebabkan morbiditas dan mortalitas. Sebanyak empat juta orang meninggal disetiap tahunnya. Penelitian ini menggunakan data sekunder sehingga dikategorikan sebagai non reactive research. Populasi yang digunakan yaitu jumlah kasus Infeksi Saluran Pernafasan Akut (ISPA) pada Laki-laki di Puskesmas Jagir Surabaya yang tercatat di Puskesmas Jagir Surabaya tahun 2013 sampai 2018 (bulanan). Pada penelitian yang menjadi variabel dependen adalah jumlah kasus Infeksi Saluran Pernafasan Akut (ISPA), sedangkan variabel independennya adalah waktu. Model yang didapat dari metode ARIMA ini adalah model $(2,0,1)$. Diperoleh hasil peramalan yaitu 354 kasus pada tahun 2019, peramalan tersebut mengalami peningkatan dari tahun 2018 yang hanya 313 kasus. Hasil dari peramalan yang sudah diperoleh, diharapkan dapat menjadi bahan acuan untuk menyusun suatu kebijakan dan sebuah program baru atau perbaikan pada program sebelumnya agar angka terjadinya kasus ISPA di Puskesmas Jagir dapat teratasi dengan baik.
\end{abstract}

Kata kunci: peramalan, autoregressive intregated moving average, infeksi saluran pernafasan akut 


\section{PENDAHULUAN}

Analisis deret berkala merupakan suatu model peramalan yang dapat dilakukan di berbagai bidang yaitu bidang pertanian, teknik, kedokteran, bahkan dapat dilakukan dalam bidang ekonomi dan bidang geofisika (Kuncoro, 2004). Pemodelan deret berkala tersebut memiliki tujuan yaitu selain untuk melakukan forecast, model deret berkala juga bertujuan untuk melakukan sebuah pengendalian serta mengenali bagaimana pola perilaku pada sistem tersebut. Analisis deret berkala memiliki berbagai macam model dilihat dari analisis hubungan dari variabel yang nantinya akan diramalkan dengan variabel independen atau waktu (Wardani \& Wihardi, 2010).

Peramalan memiliki berbagai macam metode, dari metode yang sangat mudah sampai menggunakan pendekatan yang sangat rumit. Hal tersebut dapat dilihat pola data yang akan dianalisis dan hal-hal yang bisa mempengaruhi hasil forecasting sampai ke aspek lainnya. Teknik forecasting terdiri dua macam berdasarkan penggunaannya yaitu quantitative dan qualitative. Metode quantitative terdiri dua macam yaitu time series dan kausal, sedangkan qualitative terdiri dari eksplanatori dan normatif (Makridakis, Wheelwright dan McGee, 1995).

Metode time series merupakan suatu metode peramalan yang objektif, dan metode ini sangat cocok untuk melakukan suatu peramalan dengan nilai historis yang menghasilkan nilai di masa yang akan datang yang dipengaruhi oleh nilai dari masa lampau, sehingga tidak melihat terjadinya peningkatan nilai tertentu. Pada metode ini model yang sedang diamati ini diambil secara runtun, misalnya diambil secara harian, secara mingguan bahkan tahunan (Rais, 2009). Analisis time series ini memiliki empat pola, yaitu pola horisontal, pola siklis, pola musiman, dan trend. Metode time series ini memiliki tujuan yaitu mencari pola dari data serta memperkirakan pola data tersebut ke masa yang akan datang (Makridakis, Wheelwright dan McGee, 1995).

Metode peramalan yang umum digunakan adalah metode $A R$, metode MA, serta kombinasi dari dua metode yaitu antara metode AR dan metode MA sehingga didapatkan metode ARMA, dan juga ARIMA. Metode ARIMA mempunyai beberapa perkembangan, yaitu ada ARFIMA dan SARIMA. Metode ARFIMA ini digunakan untuk meramalkan sebuah data dalam jangka pendek ataupun jangka panjang dengan model tersebut, sedangkan SARIMA dapat digunakan untuk data yang mempunyai pola musiman (Hasan, 2002).

Metode peramalan menggunakan ARIMA lebih mudah untuk diaplikasikan dalam suatu pengolahan data dibandingkan dengan ARFIMA dan SARIMA baik secara matematik ataupun dalam penggunaan komputer. ARIMA dan ARFIMA pada dasarnya sama hanya berbeda pada jangka waktu peramalannya (Darmawan, 2009).

Metode ARIMA adalah pendekatan yang membentuk model yang paling kuat dalam menganalisis data time series, serta kajian yang diberikan sangatlah teliti. Metode ini dapat memodelkan data yang stasioner ataupun yang tidak stasioner (Tsay, 2005).

Metode ARIMA ini hingga sekarang masih terus dikembangkan karena metode peramalan yang sudah ada seperti metode pemulusan exponential masih dibatasi dengan asumsi pada pola tertentu, serta pada metode exponential asumsi yang digunakan berupa pola data yang stasioner saja. Pada metode ARIMA ini tidak memerlukan asumsi yang tepat pada pola data sehingga metode ini sangat berbeda. Secara statistik, ketepatan hasil peramalan yang disajikan akan baik jika variabel dependen berhubungan satu sama lainnya (Wei, 2006). Model ARIMA dinotasikan dengan $\mathrm{p}, \mathrm{d}$, q yang mana pada model tersebut bahwa drajat AR dinotasikan (p), notasi (d) sebagai derajat pembeda dan (q) dinotasikan sebagai derajat MA (Kasanah, 2016).

Infeksi Saluran Pernafasan Akut (ISPA) adalah suatu penyakit yang menyerang bagian saluran pernafasan mulai dari hidung hingga bagian alveoli termasuk jaringan adneksanya (Irianto, 2015). Menurut WHO (2008), penyakit Infeksi Saluran Pernafasan Akut (ISPA) adalah penyakit menular yang menyebabkan morbiditas dan mortalitas. Empat juta orang meninggal setiap tahunnya, kebanyakan terkena infeksi saluran pernafasan bawah yaitu sebesar $98 \%$. Pada jenis kelamin laki-laki mudah terkena penyakit tersebut dikarenakan kebiasaan 
merokok. Satu putung rokok mengandung jutaan zat kimia yang mana zat tersebut dapat menyebabkan berbagai macam penyakit terutama penyakit pada saluran pernafasan. Tidak hanya putungnya saja yang berbahaya tetapi asap yang dihasilkan dari pembakaran rokok ini mengandung karbonmonoksida lima kali lebih besar dari pada asap rokok utamanya. Penyakit ini juga menyerang balita, anak-anak, dan orang yang sudah lanjut usia, yang terjadi di negara dengan rata-rata pendapatan per kapita rendah dan menengah (Syahidi, Gayatri dan Bantas, 2016).

Penyakit ini banyak terjadi di negara berkembang serta penyebab utama meningkatnya kunjungan pasien Puskesmas sebesar $(40 \%-60 \%)$ dan kunjungan rumah sakit sebesar (15\%-30\%). Kasus ISPA terbanyak terjadi di India, China, Pakistan, Bangladesh, Indonesia, Nigeria. Pada kasus ISPA ini terdapat $7-13 \%$ terdiri dari kasus berat sehingga memerlukan perawatan yang lebih intensif. Di Indonesia terdapat beberapa provinsi yang memiliki angka kejadian ISPA tertinggi yaitu NTT, Papua, Aceh, NTB, dan Jawa Timur. Penduduk dengan kondisi ekonomi menengah ke bawah ini lebih banyak terkena penyakit tersebut (Kemenkes RI, 2013).

Berdasarkan data dari Dinas Kesehatan Kota Surabaya, saat ini penyakit saluran pernafasan bagian atas menduduki peringkat teratas dengan jumlah 650.217 penderita atau $41 \%$ serta penyakit yang menyerang sistem otot dan jaringan pengikat menduduki peringkat kedua dengan jumlah 190.341 penderita atau $12,02 \%$ (Dinkes Kota Surabaya, 2017).

Hasil dari penelitian ini bisa digunakan oleh Puskesmas Jagir sebagai sarana untuk deteksi dini pergerakan kasus Infeksi Saluran Pernafasan Akut (ISPA) dimana informasi tersebut bisa membentuk suatu kebijakan kesehatan sehingga dapat meminimalisir peningkatan kasus Infeksi Saluran Pernafasan Akut (ISPA). Selain itu bisa sebagai perencanaan peningkatan kebutuhan layanan kesehatan, dimana dengan mempersiapkan pengobatan yang dibutuhkan dimasa mendatang untuk menangani kasus Infeksi Saluran Pernafasan Akut (ISPA).

\section{METODE PENELITIAN}

Penelitian ini menggunakan data sekunder dan termasuk jenis penelitian non reactive research (Kuntoro, 2011). Penelitian ini dilaksanakan di Puskesmas Jagir Surabaya pada bulan November 2018 hingga Januari 2019 tentang Infeksi Saluran Pernafasan Akut (ISPA). Data yang digunakan dalam penelitian ini yaitu seluruh jumlah kasus ISPA yang tercatat di laporan ICD X Puskesmas Jagir Surabaya mulai tahun 2013 sampai 2018 (data bulanan). Variabel dependen dari penelitian ini adalah jumlah kasus ISPA, sedangkan variabel independennya adalah waktu.

\section{HASIL PENELITIAN}

Kasus ISPA pada laki-laki di Puskesmas Jagir Surabaya terjadi kenaikan dan penurunan selama tahun 2013 sampai tahun 2018. Jumlah kasus yang terjadi di tahun 2013 yaitu sebesar 397 kemudian ditahun 2014 mengalami penurunan jumlah kasus ISPA sebesar 222. Pada tahun 2015 hingga 2016 ini kasus ISPA mengalami kenaikan sebesar 291 kasus di tahun 2015 dan sebesar 348 kasus ditahun 2016. Pada tahun 2017 hingga tahun 2018 mengalami penurunan jumlah kasus ISPA dimana pada tahun 2017 menurun sebesar 322 kasus dan pada tahun 2018 terjadi penurunan sebesar 313 kasus. Dapat disimpulkan bahwa kasus ISPA yang terjadi di Puskesmas Jagir memiliki pola data musiman. Hal tersebut dapat dilihat pada Gambar 1.

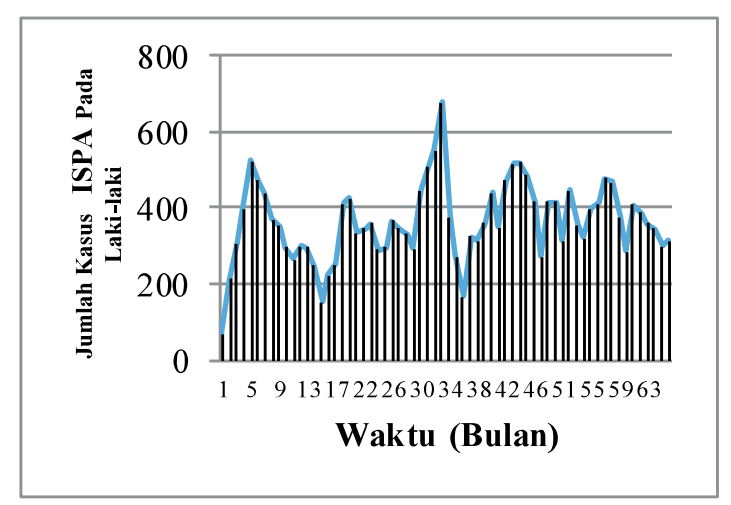

Gambar 1. Jumlah Kasus ISPA pada Laki-laki Tahun 2013-2018 di Puskesmas Jagir Surabaya 


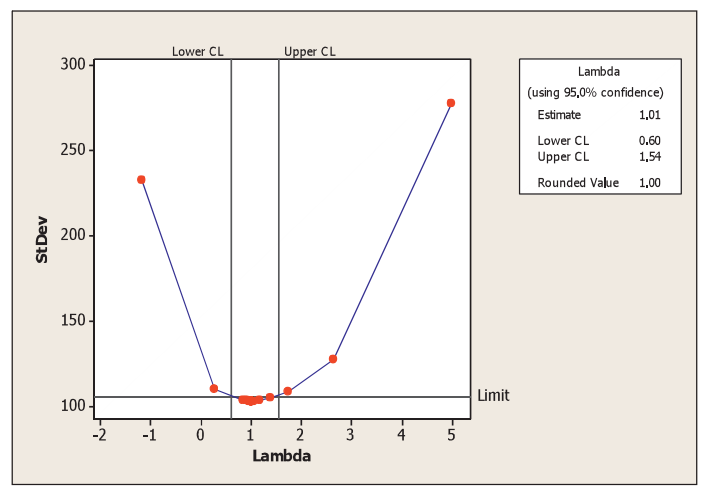

Gambar 2. Hasil Uji Box-cox pada Data Jumlah Kasus ISPA pada Laki-laki Tahun 2013-2018 di Puskesmas Jagir Surabaya

Tabel 1. Hasil Uji Stasioner dalam Rataan pada Jumlah Kasus ISPA Laki-laki di Puskesmas Jagir Surabaya

\begin{tabular}{ccc}
\hline & t-Statistic & Prob.* $^{*}$ \\
\hline Augmented Dickey- & -4.528564 & 0.0005 \\
Fuller test statistic & & \\
Test critical values: & & \\
$1 \%$ level & -3.538362 & \\
$5 \%$ level & -2.908420 & \\
$10 \%$ level & -2.591799 & \\
\hline
\end{tabular}

Berdasarkan Gambar 2, data yang ada telah stasioner dalam varians karena mempunyai nilai Rounded Value yaitu 1,00, sehingga tidak membutuhkan transformasi. Data tersebut telah stasioner dalam rataan karena memiliki nilai probabilitas yang lebih kecil 0,0005 dibandingkan dengan $\alpha 0,05$, sehingga tidak membutuhkan differencing. Hal tersebut dapat dibuktikan pada Tabel 1.

\section{Identifikasi Model Sementara}

Gambar 3 menunjukkan plot dari ACF dan PACF yang mana tidak menggunakan nilai differencing karena data tersebut telah stasioner dalam varian ataupun rataan maka nilai $\mathrm{d}=0$. Plot PACF menunjukkan bahwa plot $\mathrm{AR}=0,1,2,3$ dan pada plot ACF menunjukkan bahwa plot $\mathrm{MA}=$ $0,1,2$. Dapat disimpulkan bahwa dengan melihat gambar 3, model yang didapat adalah ARIMA

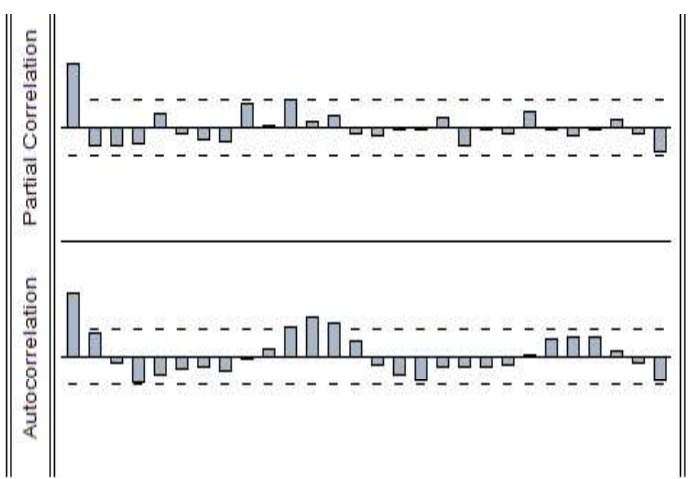

Gambar 3. Plot ACF dan PACF pada Jumlah Kasus ISPALaki-laki di Puskesmas Jagir Surabaya

$(0,0,1),(0,0,2),(0,0,3),(1,0,0),(1,0,1),(1,0,2)$, $(1,0,3),(2,0,0),(2,0,1),(2,0,2)$ dan $(2,0,3)$.

\section{Estimasi Parameter}

Uji nilai probabilitas pada parameter model sementara dalam Tabel 2 digunakan untuk menguji model ARIMA yang telah didapatkan pada tahap sebelumnya untuk menguji kelayakan dari model yang telah didapatkan. Model dikatakan signifikan dan layak apabila memiliki nilai probabilitas dari semua variabel yaitu $\leq$ 0,05 dan juga $t$-statistic dari semua variabel $\geq$ t-tabel. Terdapat 7 model yang tidak lolos terhadap uji signifikan dikarenakan memiliki nilai probabilitas $\geq 0,05$ dan terdapat 4 model yang lolos uji signifikan dikarenakan ke-4 model tersebut memiliki nilai probabilitas $\leq 0,05$.

\section{Uji Diagnostik Model ARIMA}

Uji diagnostik model ini digunakan untuk mengetahui model yang didapat bersifat acak dan homogeny. Model dikatan layak dan dapat diterima apabila rata-rata nilai probabilitas $\geq$ 0,05 yang berarti sisaan tidak memiliki pola tertentu lagi atau bersifat acak, dan varian dari sisaan bersifat homogen. Berdasarkan pada tabel 4 model yang didapat yaitu $(1,0,0)$ dan $(2,0,1)$.

\section{Pemilihan Model Terbaik}

Berdasarkan hasil perbandingan antara nilai AIC dan SIC maka model yang terbaik yaitu model ARIMA $(2,0,1)$ dimana model tersebut memiliki nilai AIC dan SIC lebih kecil dari pada model $(0,0,1)$. 
Tabel 2. Hasil Uji Signifikan Nilai Probabilitas Model Sementara pada Jumlah Kasus ISPA Laki-laki di Puskesmas Jagir Surabaya

\begin{tabular}{lcc}
\hline Model ARIMA & Nilai Probabilitas & Keterangan \\
\hline ARIMA $(0,0,1)$ & $0,0000 \mathrm{MA}(1)$ & Signifikan \\
ARIMA $(0,0,2)$ & $0,0000 \mathrm{MA}(2)$ & Signifikan \\
ARIMA $(0,0,3)$ & $0,5029 \mathrm{MA}(3)$ & Tidak Signifikan \\
ARIMA $(1,0,0)$ & $0,648521 \mathrm{AR}(1)$ & Signifikan \\
ARIMA $(1,0,1)$ & $0,0069 \mathrm{AR}(1)$ dan $0,4220 \mathrm{MA}(1)$ & Tidak Signifikan \\
ARIMA $(1,0,2)$ & 0,0000 AR $(1)$ dan $0,8220 \mathrm{MA}(2)$ & Tidak Signifikan \\
ARIMA $(1,0,3)$ & 0,0000 AR (1) dan 0,5599 MA (3) & Tidak Signifikan \\
ARIMA $(2,0,0)$ & 0,0395 AR $(2)$ & Tidak Signifikan \\
ARIMA $(2,0,1)$ & 0,0010 AR (2) dan 0,0000 MA (1) & Signifikan \\
ARIMA $(2,0,2)$ & 0,1784 AR (2) dan 0,0000 MA (2) & Tidak Signifikan \\
ARIMA $(2,0,3)$ & 0,0168 AR (2) dan 0,1459 MA (3) & Tidak Signifikan \\
\hline
\end{tabular}

Tabel 3. Nilai Parameter Model ARIMA $(0,0,1),(0,0,2),(1,0,0)$, dan $(2,0,1)$ pada Jumlah Kasus ISPA Laki-laki di Puskesmas Jagir Surabaya

\begin{tabular}{lcc}
\hline Model ARIMA & Constanta & Nilai Probabilitas \\
\hline ARIMA $(0,0,1)$ & 22,435 & $0,0000 \mathrm{MA}(1)$ \\
ARIMA $(0,0,2)$ & 20,369 & $0,0000 \mathrm{MA}(2)$ \\
ARIMA $(1,0,0)$ & 14,403 & $0,648521 \mathrm{AR}(1)$ \\
ARIMA $(2,0,1)$ & 13,295 & $0,0010 \mathrm{AR}(2)$ dan $0,0000 \mathrm{MA}(1)$ \\
\hline
\end{tabular}

Tabel 4. Hasil Uji Diagnostik Model ARIMA $(0,0,1),(0,0,2),(1,0,0)$, dan $(2,0,1)$ pada Jumlah Kasus ISPA Laki-laki di Puskesmas Jagir Surabaya

\begin{tabular}{ccccc}
\hline \multirow{2}{*}{ Model ARIMA } & \multicolumn{2}{c}{ Rata-Rata Nilai Probabilitas } & \multicolumn{2}{c}{ Keterangan } \\
\cline { 2 - 5 } & Uji Keacakan & Uji Homogenitas & Uji Keacakan & Uji Homogenitas \\
\hline ARIMA $(0,0,1)$ & $<0,05$ & $>0,05$ & TIDAK Signifikan & Signifikan \\
ARIMA $(0,0,2)$ & $<0,05$ & $>0,05$ & TIDAK Signifikan & Signifikan \\
ARIMA $(1,0,0)$ & $>0,05$ & $>0,05$ & Signifikan & Signifikan \\
ARIMA $(2,0,1)$ & $>0,05$ & $>0,05$ & Signifikan & Signifikan \\
\hline
\end{tabular}

Tabel 5. Hasil Pemilihan Model Terbaik pada Jumlah Kasus ISPA Laki-laki di Puskesmas Jagir Surabaya

\begin{tabular}{cccc}
\hline Model ARIMA & R-Squared & AIC & SIC \\
\hline ARIMA $(0,0,1)$ & 0,336590 & $1,176,796$ & $1,186,916$ \\
ARIMA $(2,0,1)$ & 0,401291 & $1,170,258$ & $1,183,751$ \\
\hline
\end{tabular}

\section{Hasil Peramalan}

Berikut ini adalah hasil peramalan dengan menggunakan model ARIMA $(2,0,1)$ pada data jumlah kasus ISPA pada Laki-laki di Puskesmas Jagir Surabaya. 
Tabel 6. Hasil Peramalan ARIMA $(2,0,1)$ Pada Tahun 2019 di Puskesmas Jagir Surabaya

\begin{tabular}{cc}
\hline Bulan & Hasil Peramalan \\
\hline Januari 2019 & 323 \\
Februari 2019 & 339 \\
Maret 2019 & 341 \\
April 2019 & 349 \\
Mei 2019 & 348 \\
Juni 2019 & 352 \\
Juli 2019 & 351 \\
Agustus 2019 & 353 \\
September 2019 & 352 \\
Oktober 2019 & 354 \\
November 2019 & 353 \\
Desember 2019 & 354 \\
\hline
\end{tabular}

\section{PEMBAHASAN}

Berdasarkan data dari Puskesmas Jagir, kasus ISPA ini menduduki nomor satu dari 10 penyakit terbanyak di Puskesmas Jagir tahun 2016 (Tribulan 2) yaitu sebanyak 5748 penderita atau $41 \%$ selain itu peringkat kedua diduduki oleh Hipertensi yaitu sebesar 2038 penderita atau $14 \%$. Metode peramalan ARIMA merupakan model time series yang memiliki nilai observasi saling berhubungan. Metode ARIMA ini dapat menganalisis berbagai jenis data, yang mana mengandung pola musiman ataupun pola trend. Metode ini memiliki tujuan yaitu untuk menentukan hubungan statistik yang baik, antar variabel yang akan diramalkan dengan nilai historis variabel-variabel yang telah ditentukan sehingga peramalan dapat dilakukan dengan model tersebut.

Tahap awal dalam meramalkan suatu kasus yaitu yang pertama adalah melihat apakah data yang nantinya akan dilakukan peramalan sudah stasioner dalam varian ataupun stasioner dalam rataan, jika data tersebut belum stasioner dalam varian maka data tersebut perlu dilakukan transformasi, tetapi jika data tersebut tidak stasioner dalam rataan maka data tersebut perlu dilakukan differencing. Pada data jumlah kasus ISPA di Puskesmas Jagir ini tidak perlu dilakukan transformasi ataupun differencing karena data tersebut telah stasioner dalam varian ataupun dalam rataan, maka data tersebut dapat dilanjutkan ketahap berikutnya.

\section{Identifikasi Model Sementara}

Tahap kedua dari metode ARIMA ini yaitu dengan mengidentifikasi model sementara yang mana bertujuan untuk melihat dan menetapkan nilai dari AR, $d$, MA. Nilai AR dan MA ditentukan dengan meninjau dari hasil perpotongan yang ditunjukkan gambar ACF dan gambar PACF yang mana mempunyai nilai confidence level.

Berdasarkan hasil identifikasi model sementara didapatkan model ARIMA sebagai berikut: ARIMA $(0,0,1),(0,0,2),(0,0,3),(1,0,0)$, $(1,0,1),(1,0,2),(1,0,3),(2,0,0),(2,0,1),(2,0,2)$ dan $(2,0,3)$, sehingga kesebelas model tersebut dapat dilanjutkan ketahap berikutnya.

\section{Estimasi Parameter}

Tahap ketiga ini untuk mencari tahu dan menentukan parameter apa saja yang signifikan dan yang diperlukan. Agar dapat menentukan estimasi parameter, maka dalam penelitian ini dibantu dengan aplikasi komputer. Bentuk model yang signifikan yaitu mamiliki nilai probabilitas dari semua variabel yaitu $\leq 0,05$ dan juga $t$-statistic dari semua variabel $\geq \mathrm{t}$-tabel.

Terdapat 7 model yang tidak signifikan terhadap nilai probabilitas dikarenakan memiliki nilai probabilitas $\geq 0,05$ dan terdapat 4 model yang signifikan terhadap nilai probabilitas, dikarenakan keempat model tersebut mempunyai nilai probabilitas kurang dari 0,05 , maka dapat diteruskan ke tahap selanjutnya yaitu pemeriksaan diagnostik model.

\section{Pemeriksaan Diagnosa}

Tahap keempat dari peramalan dengan metode ARIMA yaitu dengan melakukan pemeriksaan diagnosa tujuan pemeriksaan ini untuk mencari tahu apakah model sementara layak ke tahap selanjutnya atau tidak. Dalam pengecekan ini terdapat tiga pengujian, yaitu uji signifikansi rata-rata nilai probabilitas, uji keacakan, dan uji homogenitas. model dikatan layak dan dapat diterima apabila rata-rata nilai 
probabilitas $\geq 0,05$ yang berarti sisaan tidak memiliki pola tertentu lagi atau bersifat acak, dan varian dari sisaan bersifat homogen.

Hasil dari pemeriksaan diagnostik model ini terdapat dua model yang lolos dari uji keacakan dan uji homogenitas, model yang didapat yaitu $(1,0,0)$ dan $(2,0,1)$ dikarenakan keduanya memiliki nilai probabilitas rata-rata yaitu $\leq 0,05$. Pada model $(1,0,0)$ mempunyai nilai $R$-Squared sebesar 0,377388 dan pada model $(2,0,1)$ memiliki nilai $R$-squared sebesar 0,401291, sehingga kedua model tersebut dapat dilanjutkan ke tahap berikutnya yaitu pemilihan model terbaik.

\section{Pemilihan Model Terbaik}

Tahap kelima ini yaitu menentukan model yang terbaik yang mana telah lolos pada tahap sebelumnya, cara menentukan model yang terbaik yaitu dengan membandingkan tiga nilai yaitu nilai AIC, nilai SIC, dan nilai $R$-Squared. Model yang memiliki nilai AIC dan SIC paling kecil adalah model yang terbaik, sedangkan untuk menentukan model paling baik ditinjau dari nilai $R$-Squared maka yang dilihat adalah nilai paling besar.

Hasil dari perbandingan antara nilai AIC, SIC, dan $R$-Squared maka model yang terbaik adalah model $(2,0,1)$, karena mempunyai nilai AIC dan SIC paling kecil dibandingkan dengan model $(1,0,0)$. Selain itu model $(2,0,1)$ ini untuk nilai $R$-Squared paling besar yaitu 0,401291 dibandingkan dengan model ARIMA $(1,0,0)$ yang mana mempunyai nilai $R$-Squared yaitu 0,377388 . Dapat disimpulkan bahwa untuk melakukan peramalan jumlah kasus ISPA pada Laki-laki di tahun 2019 menggunakan model $\operatorname{ARIMA}(2,0,1)$.

\section{Hasil Peramalan}

Tahap keenam atau tahap terakhir yaitu mendapatkan hasil peramalan jumlah kasus ISPA pada Laki-laki tahun 2019 dengan menggunakan model ARIMA $(2,0,1)$. Berdasarkan hasil tersebut dapat kita lihat kenaikan kasus ISPA pada Lakilaki di bulan januari hingga juni 2019 terus terjadi kenaikan.

\section{SIMPULAN DAN SARAN}

\section{Simpulan}

Hasil peneliatan jumlah kasus ISPA pada Laki-laki tahun 2019 di Puskesmas Jagir Surabaya menghasilkan 2 model terbaik yaitu model $(0,0,1)$ dan model $(2,0,1)$. Kedua model tersebut telah melalui banyak uji dan syarat guna mencari model yang terbaik untuk dilakukan peramalan jumlah kasus ISPA pada Laki-laki tahun 2019 di Puskesmas Jagir Surabaya, kemudian dilakukan perbandingan antara nilai AIC dan SIC pada kedua model tersebut. Setelah dilakukan perbandingan antara nilai AIC dan SIC maka model yang paling baik adalah model $(2,0,1)$ dimana model ARIMA $(2,0,1)$ ini dengan nilai AIC dan SIC terkecil dibandingkan dengan model $(0,0,1)$ dimana model tersebut mempunyai nilai AIC dan SIC yaitu 11,76796 dan 11,86916. Model $(2,0,1)$ ini mempunyai nilai $R$-squared yaitu 0,401291 .

Hasil forecasting pada jumlah kasus ISPA pada laki-laki di Puskesmas Jagir Surabaya ini pada bulan Januari hingga bulan Juni 2019 terus mengalami peningkatan jumlah kasus ISPA pada laki-laki sedangkan di bulan Juli hingga Desember bersifat stagnan.

\section{Saran}

Hasil dari forecasting yang sudah diperoleh, diharapkan dapat menjadi bahan acuan untuk menyusun suatu kebijakan dan sebuah program baru atau perbaikan pada program sebelumnya agar angka terjadinya kasus ISPA di Puskesmas Jagir dapat teratasi dengan baik dan tepat pada sasaran, sehingga jumlah kasus ISPA tersebut dapat mengalami penurunan secara perlahanlahan.

\section{DAFTAR PUSTAKA}

Darmawan, G., 2009. Perbandingan Metode Peramalan ARIMA dan ARFIMA pada Data Long Memory. Jurnal Statistika, 9(2), pp.109-113.

Dinkes Kota Surabaya, 2017. Profil Kesehatan Kota Surabaya Tahun 2016. Surabaya: Dinas Kesehatan Kota Surabaya. 
Hasan, I., 2002.Pokok-Pokok Materi Metodologi Penelitian dan Aplikasinya. Bogor: Ghalia Indonesia.

Irianto, K., 2015. Memahami Berbagai Macam Penyakit. Bandung: Alfabeta.

Kasanah, L.N., 2016. Aplikasi Autoregressive Integrated Moving Average (ARIMA) untuk Meramalkan Jumlah Demam Berdarah Dengue (DBD) di Puskesmas Mulyorejo. Jurnal Biometrika dan Kependudukan, 5(2), pp.177-186.

Kemenkes RI, 2013. Riset Kesehatan Dasar. Jakarta: Badan Penelitian dan Pengembangan Kesehatan Kementerian Kesehatan Republik Indonesia.

Kuncoro, M., 2004. Model Kausal: Dasar-Dasar Metode ARIMA (Box-Jenkins). Jakarta: Erlangga.

Kuntoro, 2011. Dasar Filosofis Metodologi Penelitian. Surabaya: Pustaka Melati.

Makridakis, S., Wheelwright, S.. and McGee, V., 1995. Metode dan Aplikasi Peramalan Jilid 1. Jakarta: Erlangga.
Rais, 2009. Pemodelan Data Time Series dengan Metode Box-Jenkins. JIMT, 6(1), pp.1-10.

Syahidi, M.H., Gayatri, D., Bantas, K., 2016. Faktor-faktor yang Mempengaruhi Kejadian Infeksi Saluran Pernapasan Akut (ISPA) pada Anak Berumur 12-59 Bulan di Puskesmas Kelurahan Tebet Barat, Kecamatan Tebet, Jakarta Selatan, Tahun 2013. Jurnal Epidemiologi Kesehatan Indonesia, 1(1), pp.23-27.

Tsay, R.S., 2005. Analysis of Financial Time Series: Financial Econometrics. Canada: John Wiley \& Sons, Inc.

Wardani, I.G.A.K., Wihardi, K., 2010. Penelitian Tindakan Kelas. Jakarta: Universitas Terbuka.

Wei, W.W.S., 2006. Time Series Analysis: Univariate and Multivariate Methods. 2nd ed. United States of America: Pearson Education, Inc.

WHO, 2008. Infeksi Saluran Pernapasan Akut (ISPA) yang Cenderung Menjadi Epidemi dan Pandemi di Fasilitas Pelayanan Kesehatan. Jenewa: World Health Organization. 